\title{
Palavras, que as há
}

\author{
If there are words
}

\section{Alina Villalva Universidade de Lisboa}

\section{Resumo}

Partindo de referências a trabalhos anteriores e de algumas novas reflexōes, faz-se um convite à discussão de questões em aberto no domínio da investigação em morfologia, como as que dizem respeito à adequação do princípio da atomicidade das palavras, ao lugar da morfologia na gramática e à necessidade de cruzamento das abordagens histórica e sincrônica no conhecimento das palavras.

\section{Palavras-Chave}

Morfologia, Definição de palavra, Bases de dados lexicais, Morfologia histórica

\section{Abstract}

This paper is an invitation to discuss open questions in the domain of morphology, such as the adequacy of the principle of atomicity for words, the place of morphology in the architecture of grammar, and the necessity to mingle historical and synchronic approaches to increase the knowledge of words.

\section{Keywords}

Morphology, Word definition, Lexical database, Historical morphology. 


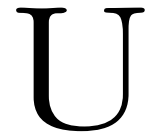

m ponto de vista não pode deixar de ser pessoal e circunstancial. $\mathrm{Na}$ discussão sobre o que tem sido, o que é e o que será a morfologia, no domínio da linguística, é bom lembrar que haverá opinióes muito distintas, como na interpretação da imagem que aqui reproduzo: a projeção do objeto flutuante na parede da direita mostra um círculo; na parede da esquerda aparece um retângulo; mas o objeto representado é, na verdade, um cilindro. Gosto de olhar para a morfologia como olho para o cilindro, e não para o retângulo ou o círculo que certos olhares também permitem ver.

Não há nada no termo 'morfologia' que leve a pensar em palavras, tal como não há nada em 'sintaxe' que apenas diga respeito a frases. Nem as palavras são só forma nem a forma é sempre uma palavra. Essa quase denegação do objeto de estudo próprio da morfologia tem sido bem acompanhada, primeiro, pela redução da morfologia à categorização das unidades frásicas terminais e à descrição dos seus paradigmas de variação formal; e depois, pela explicação dos processos morfológicos, que quase sempre eram apenas processos de flexão, em termos dominantemente fonológicos e sintáticos.

A natureza mais evidentemente sistemática da flexão favorecia esse tipo de abordagens e as 'irregularidades' não preocupavam ninguém, dada a longuíssima tradição de aprendizagem desses paradigmas flexionais excepcionais, caso a caso. 
A formação de palavras demorou muito mais tempo a encontrar uma abordagem propícia. Os princípios da análise estruturalista permitiram compreender alguns problemas de segmentação, mas o avanço no conhecimento das propriedades gramaticais dos afixos e na compreensão das estruturas das palavras complexas é ainda um fato recente, dos últimos 30 a 40 anos.

As entrevistas ${ }^{1}$ de 2009 a Mark Aronoff e Margarida Basílio, dois autores de relevo na investigação em morfologia, ${ }^{2}$ são leitura que recomendo a quem pretenda ficar a conhecer os momentos decisivos e as referências incontornáveis na história moderna deste domínio da gramática. Não vou, pois, tentar voltar a fazer o que aí está tão bem feito. Não quero, aliás, perder a oportunidade de referir que os estudos de morfologia aparentam estar a passar por um bom momento no Brasil, tendo em conta sinais como o da recente realização do I Congresso Internacional de Estudos do Léxico (Salvador, da Bahia, Abril 2011) e do I Colóquio Brasileiro de Morfologia (Porto Alegre, Maio de 2011), ${ }^{4}$ com posterior publicação de alguns dos trabalhos aí apresentados, ${ }^{5}$ mas também com larga produção académica e bastantes monografias disponibilizadas no mercado editorial.

Em resposta ao convite dos editores da RELIN, que muito me honrou, o que aqui pretendo desenvolver, a partir de referências a trabalhos anteriores e de algumas novas reflexões, é um convite à discussão de questôes em aberto no domínio da investigação em morfologia, como as que dizem respeito à adequação do princípio da atomicidade das palavras, ao lugar da morfologia na gramática e à necessidade de cruzamento das abordagens histórica e sincrónica no conhecimento das palavras. Terminarei com uma nota sobre o Português.

\section{Sobre a atomicidade das palarras}

Não está fechada a questão da existência das palavras como unidades de análise linguística, nem a da definição do que estas unidades possam ser, de quais são as suas especificidades, do que as distingue das unidades frásicas que integram, nem de como se afastam do que sejam as peças que as constituem. Para o senso comum, palavra é um conceito acessível, um conceito que faz parte de um conhecimento pré-escolar assente na nomeação dos objetos que acompanha o desenvolvimento das crianças, que também faz parte da experiência académica em que a reflexão sobre a gramática da língua ocupa, de forma constante, um lugar variável, e que não é esquecido ao longo da vida. E, no entanto, no domínio da análise linguística pós-saussureana, é palavra a unidade mais frequentemente 
posta em causa e a comparação entre línguas mostra que não é fácil encontrar definiçōes de palavra que resistam facilmente à diversidade do que as múltiplas tradições linguísticas chamam palavra.

Os critérios usados para a identificação das palavras passam frequentemente por constataçôes, como as seguintes:

a. as palavras são um domínio de acentuação;

b. as palavras exibem um padrão de acentuação regular e distinto do de outras unidades;

c. a afixação só ocorre no interior do domínio de uma palavra;

d. as palavras podem ser movidas ou extraídas na frase, os seus constituintes não; e

e. a menor unidade que pode constituir uma frase é uma palavra.

Todos esses critérios oferecem problemas e requerem comentários que, em geral, permitem resolver aparentes ou reais contradiçōes. Pensando apenas em dados do Português, pode admitir-se, entre outras possibilidades, que:

a. os clíticos são um problema, mas podem ser analisados como afixos, ou então considera-se que a palavra que é um domínio de acentuação é distinta da palavra que é uma unidade sintática;

b. há palavras, como as que contêm sufixos z-avaliativos e os advérbios em - mente, que exibem padrões acentuais distintos do padrão canónico, mas a admissão de que as palavras fonológicas são distintas das unidades sintáticas terminais também resolve este problema;

c. os z-avaliativos e os advérbios em - mente são palavras formadas por sufixação a palavras, mas essa é uma possibilidade que as propriedades de seleção dos afixos provavelmente admitem; também há que resolver a coordenação de prefixos (cf. pré e pós-parto) e a coordenação de advérbios em -mente (cf. lenta e progressivamente), o que pode sugerir que a análise dos clíticos como afixos deve ser uma hipótese a considerar num quadro mais alargado;

d. não conheço contraexemplos de movimento ou extração de constituintes de palavras, pelo que este parece ser um critério sólido;

e. só alguns tipos de palavras (i. e. nomes, verbos, adjetivos, advérbios - mas nem sequer todas as palavras destas categorias) podem ocorrer em holófrase, o que deixa por resolver o problema de como tratar as palavras que não podem ocorrer neste tipo de frases. 
Tenho dedicado boa parte do meu trabalho a essa discussão e à defesa de uma definição de palavra enquanto unidade morfológica que não se sobrepõe à sua definição nem na sintaxe, nem na fonologia nem na semântica. Em traços largos, o que tenho defendido ${ }^{6}$ é que, enquanto unidades morfológicas, as palavras são caracterizáveis como projeções máximas de um radical, obtidas por especificação morfológica (realizada por um constituinte temático) e por especificação morfossintática (realizada pela flexão morfológica), ainda que, em circunstâncias particulares, estas posições estruturais possam estar vazias:?

$$
\left[\left[[\mathrm{X}]_{\text {radical }}[\mathrm{Y}]_{\text {constituinte temático }}\right]_{\text {tema }}[\mathrm{Z}]_{\text {flexão }}\right]_{\text {palavra }}
$$

A estrutura morfológica das palavras complexas é obtida por ramificação do radical, pelo que as palavras complexas são, na verdade, radicais complexos nos quais se pode acomodar uma estrutura de derivação (por sufixação), de modificação (por prefixação ou sufixação) ou de composição (de radicais):

$$
\begin{aligned}
& {\left[\left[\left[\mathrm{X}_{\text {base }}[\mathrm{W}]_{\text {sufixo derivacional }}\right]_{\text {radical derivado }}[\mathrm{Y}]_{\text {constituinte etemático }}\right]_{\text {tema }}[\mathrm{Z}]_{\text {flexáo }}\right]_{\text {palavra }}} \\
& \left.\left[\left[\mathrm{X}_{\text {base }}[\mathrm{W}]_{\text {suffixo modificador }}\right]_{\text {radical modificado }}[\mathrm{Y}]_{\text {constituinte temático }}\right]_{\text {tema }}[\mathrm{Z}]_{\text {flexão }}\right]_{\text {palavra }} \\
& {\left[\left[\left[[\mathrm{W}]_{\text {prefixo modificador }} \mathrm{X}_{\text {base }}\right]_{\text {radical modificado }}[\mathrm{Y}]_{\text {conssitiuinte remático }}\right]_{\text {tema }}[\mathrm{Z}]_{\text {flexáo }}\right]_{\text {palavra }}}
\end{aligned}
$$

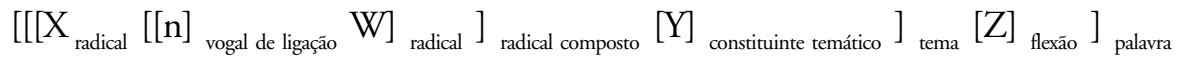

Tenho discutido essa hipótese sobre a estrutura das palavras complexas face a construções mais problemáticas, como as parassintéticas ${ }^{8}$ e as estruturas convergentes, ${ }^{9}$ particularmente no que diz respeito ao princípio de ramificação binária e à necessidade de refinar o conhecimento das propriedades dos constituintes morfológicos, mas a questão continua em aberto.

Não vou aqui retomar os argumentos anteriormente apresentados, mas trago três novas observaçôes. A primeira diz respeito ao conceito de gramaticalidade. A aceitabilidade $v s$. inaceitabilidade de uma frase é uma propriedade correlacionada com a sua boa formação, decidida pela coerência interna da gramática do(s) falante(s). Pode haver variação interpessoal ou interdialetal, mas os juízos de gramaticalidade mantêm-se estáveis no quadro de uma dada gramática. Esse conceito de gramaticalidade não parece fazer qualquer sentido quando aplicado a palavras. A questão que se coloca com maior frequência diz respeito à sua existência, mas a resposta que os falantes procuram éa que provém de uma autoridade (geralmente 
um dicionário) e não a que encontrariam na sua própria competência. Essa é uma óbvia distinção entre palavras e frases.

A segunda observação diz respeito à possibilidade de enumeração. Não será fácil conseguir listar todas as palavras de uma língua, nem de um dialeto, nem se consegue saber com segurança qual é o conjunto de palavras do léxico de um falante, tendo em conta as diferenças entre léxico passivo e léxico ativo, e sem esquecer que o léxico dos falantes varia ao longo da sua vida (crescerá sempre, exceto quando há lesões cerebrais?). Há muito trabalho de pesquisa já feito, ${ }^{10}$ há projetos em curso, há estimativas disponíveis (geralmente não muito fiáveis) e há muitíssimas listagens resultantes de estudos de caso, mas há mais dúvidas do que certezas. No entanto, a diferença entre a enumeração de palavras e a enumeração de frases é abismal. A enumeração de frases só ocorre com expressōes fixas ou semifixas, frases feitas cuja ocorrência no discurso dos falantes é certamente baixa. Aliás, quando essa frequência aumenta, cria-se um efeito de desconforto. Em geral, as frases não se armazenam, as palavras, sim.

A terceira observação prende-se com o tipo de atuação dos processos morfológicos face ao tipo de intervenção dos processos sintáticos. É concebível que a produção de frases dependa sempre de operações sintáticas. Já o uso de palavras que requerem a intervenção de processos morfológicos de formação de radicais parece depender mais da memória lexical do que da efetiva atuação desses processos. Sirvo-me de dois exemplos. O primeiro é o do advérbio portuguesmente. É sabido que esse advérbio não tem a forma *portuguesamente, porque terá sido gerado num momento em que o adjetivo português era invariável. Ainda que se possa admitir que a forma gerada a partir do adjetivo feminino não ocorre por bloqueio desencadeado pela forma derivada do adjetivo masculino, o que a intercedência desse bloqueio mostra é que o acesso à memória lexical prevalece sobre a geração casuística. Uso esse exemplo porque a formação de advérbios em -mente é, hoje em dia, muitíssimo produtiva e muito pouco constrangida.

$\mathrm{O}$ segundo exemplo diz respeito à escolha entre sufixos concorrentes. Consideremos os agentivos -dor, -nte e -ista, que ocorrem em palavras como apresentador, representante e projetista. Nada nos impede de usar, em paralelo com essas formas, formas geradas por outro dos sufixos concorrentes, mas essa possibilidade não é, regra geral, aproveitada ou nem sequer aceita (cf. *apresentante, * representador, ${ }^{*}$ projetador, ${ }^{*}$ projetante). É provável que a não ocorrência dessas formas se deva ao registro lexical das anteriores, que impedirá a posterior formação 
de palavras provavelmente 'sinónimas'. É, porém, interessante notar que é possível atestar palavras que pertencem a pares de formas concorrentes como fumador / fumante ou desenhador / desenhista, nas variedades europeia e brasileira do Português, o que mostra que, sendo palavras bem formadas e semanticamente equivalentes, a sua coexistência se deverá ao fato de pertencerem a léxicos distintos, mas a motivação destas diferentes escolhas não é conhecida. Talvez esse seja um domínio para a investigação no quadro da Teoria da Otimidade. ${ }^{11}$

Em suma, a consideração das palavras como unidades de análise distintas encontra muitos argumentos favoráveis, mas falta uma visão de conjunto, integradora e capaz de formular um sólido algoritmo que descreva a especificidade dessas unidades linguísticas.

\section{O léxico e a morfologia num modelo de gramática}

Uma outra linha de debate é a que diz respeito à discussão acerca do lugar que o léxico e a morfologia ocupam num modelo de gramática. A esse propósito, gostaria de retomar a referência a Di Sciullo e Williams (1987), porque me parece que o percurso teórico aí desenhado não foi desenvolvido como mereceria, embora nele se encontrem muitos dos pressupostos da atual corrente dominante, a da morfologia distribuída.

A abordagem da morfologia distribuída é herdeira da chamada 'split morphology hypothesis', segundo a qual toda a morfologia sintaticamente relevante, tipicamente a flexão, é tratada sintaticamente; todo o resto é tratado fora da sintaxe, tipicamente no léxico. A discussão dessa proposta, cujos autores de referência são Perlmutter (1988) e Anderson (1982), baseou-se frequentemente na discussão sobre a distinção entre flexão e derivação e, consequentemente, também na discussão sobre o momento da inserção das unidades lexicais nas estruturas sintáticas. A reação suscitada deu origem à formulação da chamada 'hipótese lexicalista forte' ou 'morfologia lexical', preconizada em Jackendoff (1972, 1975), em que a flexão e a derivação são consideradas processos indistintos, e igualmente fora do âmbito da sintaxe.

A morfologia distribuída herda dessa última abordagem a perspectiva de que a flexão e a derivação são processos semelhantes e da primeira acolhe a opção pelo processamento sintáctico. As referências clássicas relativas à morfologia distribuída são Halle e Marantz (1993, 1994), mas um dos seus seguidores, Rolf Noyer, construiu uma página web intitulada Distributed Morphology: Frequently 
Asked Questions List (www.ling.upenn.edu/ $\sim$ rnoyer/dm/), onde se encontra muita informação sobre o modelo e que serviu de inspiração à criação de uma página do mesmo tipo, em Português, pelo Grupo de Estudos em Morfologia Distribuída da USP (www.linguistica.fflch.usp.br/gremd).

Esse modelo, que se enquadra no Programa Minimalista, preconiza que as palavras e as frases são geradas pelos mesmos mecanismos: 'concatenar' e 'mover'. Esses mecanismos operam sobre 'raízes' e traços morfossintáticos que são fornecidos por um léxico empobrecido, a que é dado o nome de Lista 1, até gerarem uma estrutura sintática, puramente abstrata, que vai solicitar a interpretação fonológica dos seus nós terminais à chamada Lista 2 - o vocabulário. As unidades vocabulares são posteriormente associadas aos significados que se encontram na Lista 3, também chamada Enciclopédia.

Há, nesse modelo, virtudes e vícios. A parte que diz respeito à operação 'concatenar' não coloca problemas, pelo menos no caso das línguas que têm sistemas morfológicos concatenativos, como o Português - há concatenação nas palavras e há concatenação nas frases, ou, em termos distintos, há sintaxe nas palavras como há sintaxe nas frases. Já quanto a serem os mesmos, os princípios sintáticos que se ocupam da geração das palavras e das frases, trata-se de uma questão mais discutível. Desde logo, no que diz respeito à operação 'mover', como já antes referi, não conheço provas convincentes de movimentos no domínio das palavras. Movimentos de traços abstratos não são uma evidência substantiva.

Retomemos, então, Di Sciullo e Williams (1987). Para esses autores, as palavras são átomos sintáticos, ou seja, são unidades sintaticamente inanalisáveis. Das palavras, o que a sintaxe vêé um conjunto de traços que contém as informaçôes que a sintaxe precisa conhecer, mas que não tem reflexo na estrutura interna da palavra. ${ }^{12}$ Essa posição (que corresponde a uma reinterpretação do princípio de integridade lexical anteriormente proposto e adotado por diversos autores ${ }^{13}$ ) é sustentada pelo seguinte conjunto de argumentos:

(i) as palavras (isoladamente consideradas) têm sempre uma interpretação genérica;

(ii) a referência não é atribuída às palavras, mas, sim, às projeçôes das palavras; e

(iii) as operaçôes sintáticas (pe. movimento) não atuam no interior das palavras. 
Se, como defendem Di Sciullo e Williams (1987), as palavras são átomos sintáticos, e não há argumentos substantivos que contrariem esta hipótese, então, o princípio 'all the way down' da morfologia distribuída é inadequado.

Outras das revindicações do modelo da morfologia distribuída é a da hipótese de inserção tardia, segundo a qual a sintaxe opera sobre feixes de traços, e não sobre palavras. As palavras surgem por verificação da compatibilidade dos traços que lhe são próprios com os traços das posiçōes terminais das estruturas sintáticas. Esse é um ponto que não merece discordância, sendo até possível encontrar a sua defesa em Di Sciullo e Williams (1987, p. 53, 110), como possível causa da atomicidade sintática das palavras:

"one way to ensure syntactic atomicity of words is to place the rule of "lexical insertion after all the syntactic rules that could possibly analyze the interior constituents of words"

"syntax and morphology are parallel but independent subcomponents"

O trabalho de Di Sciullo e Williams (1987) é anterior à formulação do Programa Minimalista (cf. CHOMSKY, 1993), mas, no que diz respeito à morfologia, preconiza de algum modo a hipótese que a viria a ser consagrada, retirando a morfologia do léxico e considerando que a formação de palavras está a cargo do sistema computacional, num módulo autónomo em relação ao módulo sintático.

Em 1994, apresentei um trabalho de caracterização dos constituintes morfológicos e análise das estruturas morfológicas do Português, procurando integrar essas duas propostas (cf. VILLALVA, 1994, 2000, p. 10), na tentativa de superar "as insuficiências dos modelos que repartem a morfologia pelas diversas componentes da gramática, e as daqueles que a circunscrevem no domínio do léxico". É num quadro desse tipo, em que a morfologia e a sintaxe operam independentemente e a morfologia tem capacidade de cálculo, não se encontrando confinada no léxico, que a investigação sobre formação de palavras me parece mais interessante.

\section{O ponto de fuga}

Bruneleschi, o arquiteto que ficou famoso por ter projetado a cúpula de Santa Maria del Fiori, em Florença, também tem a si associado o mérito da recuperação dos princípios da perspetiva linear, familiar nas culturas clássicas mas 
desaprendidos durante a Idade Média. Essa técnica permite representar as três dimensões do real no plano da superfície do desenho, dando às imagens um ganho substancial em termos de verosimilhança. Essa técnica consiste em estipular um ponto de fuga, um ponto no qual o olhar se fixa e do qual partem todas as linhas que distribuem os objectos representados na ilusão da profundidade.

As dicotomias saussureanas (diacronia vs. sincronia; sintagma vs. paradigma; significante $v$ s. significado), cuja postulação permitiu olhar para as línguas de um modo fundamentadamente profícuo, fazem-me lembrar o plano no desenho e pensar se não seria tempo de as observar em perspectiva. A oposição entre diacronia e sincronia e o privilégio dado à sincronia tiveram um papel importante na busca da compreensão do funcionamento do sistema, num dado corte (num dado plano) do real, do sistema como um todo coerente e eficaz que opera, quer haja, quer não haja conhecimento da dimensão histórica de onde provém.

Said Ali é um autor de leitura cativante, particularmente a Gramática Histórica, volume que, em 1931, reúne trabalhos elaborados cerca de dez anos antes (Lexeologia do Português Histórico, 1921, e Formação de Palavras e Sintaxe do Português Histórico, 1923). Com ele aprendi a considerar a informação de natureza histórica como fundamental para o conhecimento da sincronia mais contemporânea, mas este domínio, o da morfologia histórica, não teve grande desenvolvimento no decorrer do século 20 .

Os instrumentos de análise de que dispomos atualmente permitem-nos conceber como projeto de trabalho a feitura de descrições compatíveis - que usem o mesmo aparato teórico, os mesmos conceitos, os mesmos métodos - de um conjunto de fenómenos em diferentes sincronias, por exemplo, a formação dos derivados deverbais, as construçōes parassintéticas, a composição morfológica.

O problema está no acesso aos dados, que se torna tão mais difícil quanto maior é o recuo temporal. Para já, esse acesso é praticamente impossível. Pesquisas desse tipo requerem bases de dados que não estão disponíveis para o Português. De um modo geral, as bases de dados textuais que podem ser consultadas estão feitas de um modo semiautomático, pelo que os erros de transcrição são imensos; incluem textos pela facilidade de acesso, e não por critérios de relevância lexical; há fontes repetidas; há muitas limitaçóes nas ferramentas de pesquisa. Um outro tipo de fonte é o dos dicionários, sobretudo, no caso do Português, dos dicionários feitos até o século 19. O Corpus Lexicográfico do Português ${ }^{14}$ é um projeto em curso, que procura tornar acessíveis e pesquisáveis os dicionários de referência do Português. É uma fonte incontornável. 
Recentemente, o trabalho do Grupo de Morfologia Histórica do Português (www.usp.br/gmhp/), coordenado por Mário Eduardo Viaro, tem vindo a construir e disponibilizar coleções de dados e descriçōes, sobretudo diacrónicas, de muitos sufixos do Português, havendo uma interessante recuperação dos estudos de etimologia.

Não quero sobrevalorizar as críticas às fontes disponíveis, e que se vão tornando imprescindíveis à investigação morfológica, mas gostaria de enfatizar a necessidade de suprir as falhas. A intuição dos investigadores precisa ser confirmada pelos dados. Esse é, pois, um campo de trabalho muito carente de mão-de-obra especializada.

\section{O caso do Português}

Os avanços verificados no conhecimento do sistema linguístico do Português desde meados do século 20 e, muito particularmente, desde o final desse século são muitíssimo consideráveis. Sabe-se, hoje em dia, muito mais em todos os domínios de análise relativamente a esta língua e, portanto, também em relação ao seu sistema morfológico. Cite-se, por exemplo, uma opinião de Margarida Basílio que surge, em 1999, numa descrição do estado da arte da investigação em morfologia no Brasil: ${ }^{15}$

presenciamos um desenvolvimento de estudos de morfossintaxe e fonologia lexical, ao mesmo tempo em que se consolida a singularidade da pesquisa morfológica brasileira das duas últimas décadas em torno das questões semânticas e lexicológicas envolvidas na descrição de estruturas morfológicas do português.

Por outro lado, a quantidade de estudos sobre as duas variedades mais estudadas é também bastante impressionante, mas há um problema identitário que, a esse respeito, me parece merecer alguma reflexão.

Os trabalhos de Mattoso Câmara, ${ }^{16}$ que ainda não podem ser esquecidos, e os de Herculano de Carvalho, ${ }^{17}$ que merecem maior atenção do que a que têm recebido, ${ }^{18}$ são de um tempo em que a preocupação era a de melhor conhecer o sistema linguístico do Português, e não a especificidade de cada uma das suas variedades. Essa necessidade surge mais tarde, no fio da tomada de consciência de que as descriçôes linguísticas não podem alhear-se do uso da língua pelos 
falantes e que o que se pode dizer em relação a uma dada língua é, na verdade, aferível apenas em relação a um certo dialeto dessa língua.

No caso do Português Europeu, a dimensão geográfica do país (cerca de $92.000 \mathrm{~km}^{2}$ ) ajuda a que a variação dialetal seja relativamente modesta. Não deixa, porém, de se verificar que a referência ao Português Europeu toma quase sempre o dialeto de Lisboa como base. No caso do Brasil, sendo a dimensão iniludivelmente comparável à de todo o continente europeu (cerca de 8.500.000 $\mathrm{km}^{2}$ de área total para o Brasil, e $10.000 .000 \mathrm{~km}^{2}$ para a Europa), a variação dialetal não é nunca escamoteável, pelo que as mençôes Português Brasileiro (ou Português do Brasil) carecem de maior precisão. Se o conceito de 'Português Europeu' só faz sentido se entendido como uma abstração que toma a parte pelo todo, sabendo-se qual é a parte que entra nesta equação, no de 'Português Brasileiro’, a parte não é tão fácil de identificar.

Essa é um lado do problema. O outro está relacionado com o fato de ser cada vez mais frequente encontrar em títulos de livros e de artigos sobre o Português o restritor varietal (europeu, brasileiro, etc.) em casos que não exibem qualquer contraste. Essa (im)precisão é mais frequente, no que diz respeito ao Português, do que, por exemplo, no caso do Inglês (britânico, americano, etc.), língua que também tem uma dimensão pluricontinental. É claro que essa é mais uma questão de natureza política do que linguística, mas, para quem vive quotidianamente numa situação de diglossia entre o $\mathrm{PE}$ e o $\mathrm{PB}$, a valorização das diferenças não justifica que se ignorem as semelhanças.

Em trabalhos anteriores, dedicados à comparação entre o $\mathrm{PE}$ e o $\mathrm{PB}$, defendi que os contrastes mais significativos entre essas duas variedades do Português são contrastes lexicais, contrastes absolutamente habituais na variação diatópica. Contrastes morfológicos gramaticais são difíceis encontrar, pelo que tudo parece encaixar na diferente utilização de um mesmo sistema morfológico. Será mesmo assim?

Para concluir, gostaria de dizer que a lista de questōes que enunciei superficialmente não é exaustiva-é exemplificativa e reflete as minhas preocupações dominantes. Há espaço para discuti-las e espaço ainda para muito mais.

\section{Notas}

${ }^{1}$ Estas entrevistas foram publicadas na ReVEL 7.12, um número integralmente dedicado a estudos de morfologia. 
${ }^{2}$ Cf. ARONOFF, 1976, e BASÍLIO, 1980.

${ }^{3}$ Cf. www.iciel.ufba.br/.

${ }^{4}$ Cf. coloquiodemorfologia.wordpress.com/.

${ }^{5}$ As actas do ICIEL estão em curso de publicação. A ReVEL 9.5. publicou uma seleção dos trabalhos apresentados no ICBM.

${ }^{6}$ Cf. VILLALVA, 1994, 2000, e 2008.

${ }^{7}$ Cf. VILLALVA, 2004.

${ }^{8}$ Cf. VILLALVA, 1994.

${ }^{9}$ Cf. VILLALVA, 2010.

${ }^{10}$ Cf., por exemplo, ZECHMEISTER; d'ANNA; JHALL; PAUS; SMITH, 1992. ${ }^{11}$ Veja-se, por exemplo, McCARTHY, 2006.

${ }^{12}$ Cf. Di Sciullo; Williams (1987, p. 45) "syntax do not have access to the parts of words directly, only to the "topmost" properties of word: the features and the argument structure of the topmost word".

${ }^{13}$ A série começa em CHOMSKY, 1970.

${ }^{14}$ Consultável em: clp.dlc.ua.pt/inicio.aspx.

${ }^{15}$ A Morfologia no Brasil: Indicadores e Questões. DELTA, v.15. São Paulo. Disponível em: dx.doi.org/10.1590/S0102-44501999000300003.

${ }^{16}$ Particularmente: Estrutura da Lingua Portuguesa, de 1970, e Problemas de Lingüistica Portuguesa, de 1971.

${ }^{17}$ Em especial: Teoria da Linguagem. Natureza do Fenómeno Linguístico e Análise das Linguas, de 1967.

${ }^{18}$ A Universidade de Coimbra organizou um volume de homenagem a Herculano de Carvalho em que se pode encontrar uma nota biográfica e a bibliografia deste autor. Cf. MAIA, 2006.

\section{Referências}

ANDERSON, S. Where's Morphology? Linguistic Inquiry, v. 13, p. 571-612, 1982. ARONOFF, M. Word Formation in Generative Grammar. Cambridge, Massachusetts: The MIT Press, 1976.

ARONOFF, M. Morfologia: uma entrevista com Mark Aronoff. ReVEL 7. 12, 2009. Disponível em: <www.revel.inf.br/files/entrevistas/revel_12_entrevista_ aronoff.pdf $>$. 
BASÍLIO, M. Estruturas Lexicais do Português. Petrópolis: Vozes, 1980.

BASÍLIO, M. Morfologia: uma entrevista com Margarida Basílio. ReVEL 7. 12, 2009. Disponível em: <www.revel.inf.br/files/entrevistas/revel_12_margarida_ basilio.pdf>.

CHOMSKY, N. A minimalist program for linguistic theory. In: HALE, K.; KEYSER, S. J. The View from Building 20. Cambridge, Massachusetts: The MIT Press, 1993. p. $1-52$.

DI SCIUllO, A.-M.; WILlIAMS, E. On the Definition of Word. Cambridge, Massachusetts: The MIT Press, 1987.

HALLE, M.; MARANTZ, A. Distributed Morphology and the Pieces of Inflection. In: HALE, K.; KEYSER, S. J. The View from Building 20. Cambridge, Massachusetts: The MIT Press, 1993. p. 111-176.

HALLE, M.; MARANTZ, A. Some key features of Distributed Morphology. MITWPL 21: Papers on phonology and morphology, p. 275-288, 1994.

JACKENDOFF, R. Semantic Interpretation in Generative Grammar. MIT Press: Cambridge, Massachusetts, 1972.

JACKENDOFF, R. Morphological and semantic regularities in the lexicon. Language, v. 51, p. 639-671, 1975.

MAIA, C. José Gonçalo Herculano de Carvalho (19.01.1924-26.01.2001). Esboço biográfico e académico. Miscelânea de Estudos In Memoriam José G. Herculano de Carvalho. Revista Portuguesa de Filologia, v. 25, n.1, p. 1-11, 2006.

McCARTHY, J. Morphology: Optimality Theory. Linguistics Department Faculty Publication Series. Paper 47, 2006. Disponível em: <scholarworks.umass.edu/ linguist_faculty_pubs/47>.

PERLMUTTER, D. The split-morphology hypothesis: evidence from Yiddish. In: HAMMOND, M.; NOONAN, M. (Ed.). Theoretical Morphology: Approaches in Modern Linguistics. Orlando: Academic Press, 1988.

SCHWINDT, L. C.; SCHER, A. P.; COLLISCHONN, G.; QUADROS, E. S. Apresentação: um novo retorno da Morfologia. ReVEL, edição especial, n. 5, 2011. Disponível em: <www.revel.inf.br>.

VILLALVA, A. (1994), Configurações não-binárias em morfologia. Comunicação apresentada no X Encontro da Associação Portuguesa de Linguística, 1994. Disponível em: <www.clul.ul.pt/files/alina_villalva/1994Evora_configuracoes_nao_ binarias.pdf $>$. 
VILLALVA, A. Estruturas Morfológicas. Unidades e Hierarquias nas Palavras do Português. Lisboa: FCT e FCG, 1994, 2000.

VILLALVA, A. Benefícios da diversidade: exemplos com palavras. Comunicação apresentada no Congresso Internacional "500 Anos da Lingua Portuguesa no Brasil", 2000. Disponível em: <www.clul.ul.pt/files/alina_villalva/2000Evora_Beneficios_ da_diversidade.pdf $>$.

VILLALVA, A. Vazios morfológicos. Comunicação apresentada no Congresso Internacional da Lingua Portuguesa, 2004, I. Disponível em: <www.clul.ul.pt/files/ alina_villalva/2004Florianopolis_Vazios_morfologicos.pdf $>$.

VILLALVA, A. Morfologia do Português. Lisboa: Universidade Aberta, 2008.

VILLALVA, A. Estruturas convergentes. Comunicação apresentada no Congresso Internacional de Linguistica e Filologia Românicas, 26, 2010. Disponível em: $<$ www.clul.ul.pt/files/alina_villalva/05_Villalba.pdf>.

ZECHMEISTER, E. B.; D’ANNA, C. A.; HALL, J. W.; PAUS, C. H.; SMITH, J. A. Metacognitive and other knowledge about the mental lexicon: do we know how many words we know? Applied Linguistics, v. 14, n. 2, p. 188-206, 1992. 